\title{
Concentração de flúor em águas envasadas: análise laboratorial e da legislação relacionada
}

\author{
Fluoride concentration in bottled waters: laboratory analysis and \\ related legislation
}

Cléa Adas Saliba Garbin* Arinilson Moreira Chaves Lima**

Artênio José Isper Garbin ${ }^{* * *}$ Betânia Moreira Chaves Lima ${ }^{* * * *}$

Renato Moreira Arcieri ${ }^{* * * *}$

Suzely Adas Saliba Moimaz ${ }^{* * * * *}$

\section{Resumo}

A fluoretação das águas para consumo humano é um método de prevenção da cárie que traz grande benefício social, se for mantida em teores ideais. Com o aumento da produção de águas envasadas, acentua-se a necessidade de verificar se a presença de flúor nessas águas ocorre em quantidade suficiente para prevenir a cárie, ou ainda se representa risco significativo de fluorose. Objetivo: comparar as concentrações de flúor presentes em águas envasadas com aquelas declaradas nos rótulos das embalagens, e fazer uma análise crítica das normas legais sobre o tema. Materiais e método: tratou-se de um estudo transversal, por meio do qual foram analisadas 22 amostras de águas envasadas comercializadas no estado do Ceará. As análises foram realizadas em duplicata, por meio do método eletrométrico, e os resultados obtidos foram comparados àqueles impressos nos rótulos das embalagens. Foram feitas buscas minuciosas por leis, resoluções, portarias, e outros documentos oficiais em vigor relacionados ao tema. Resultados: as concentrações de flúor encontradas variaram de 0,01 a 0,36 mgF/l. Apesar de $72,7 \%$ das amostras terem sido classificadas como fluoretadas, as concentrações de flúor observadas mostraram-se insuficientes para a prevenção da cárie. Quanto às normas, foram encontradas situações, em que essas não são claras, ou até mesmo divergentes. Considerações finais: a legislação vigente sobre $o$ assunto necessita de atualizações para se tornar mais objetiva e para criar novos critérios sobre o uso da expressão "água fluoretada".

Palavras-chave: Água envasada. Fluoretos. Legislação sanitária. Rotulagem de produtos.

\section{Introdução}

A fluoretação das águas de abastecimento público para consumo humano, quando realizada na concentração ideal, de acordo com a média das temperaturas máximas de cada região é um método reconhecido na prevenção da cárie dentária ${ }^{1}$. Apresenta alta eficiência, baixo custo relativo e grande bene-

Livre-docente; professora adjunta do Departamento de Odontologia Infantil e Social da Faculdade de Odontologia de Araçatuba, Universidade Estadual Paulista Júlio de Mesquita Filho (Unesp), Araçatuba, São Paulo, SP, Brasil.

Mestre em Odontologia; doutorando do programa de Pós-Graduação em Odontologia Preventiva e Social da Faculdade de Odontologia de Araçatuba, Universidade Estadual Paulista Júlio de Mesquita Filho (Unesp), Araçatuba, São Paulo, SP, Brasil.

Livre-docente; professor adjunto do Departamento de Odontologia Infantil e Social da Faculdade de Odontologia de Araçatuba, Universidade Estadual Paulista Júlio de Mesquita Filho (Unesp) Araçatuba, São Paulo, SP, Brasil.

***** Especialista em Saúde Pública; enfermeira da Prefeitura Municipal de Limoeiro do Norte, Ceará, CE, Brasil.

***** Livre-docente; professor adjunto do Departamento de Odontologia Infantil e Social da Faculdade de Odontologia de Araçatuba, Universidade Estadual Paulista Júlio de Mesquita Filho (Unesp), Araçatuba, São Paulo, SP, Brasil.

****** Livre-docente; professora titular do Departamento de Odontologia Infantil e Social da Faculdade de Odontologia de Araçatuba, Universidade Estadual Paulista Júlio de Mesquita Filho (Unesp), Araçatuba, São Paulo, SP, Brasil. 
fício social ${ }^{2}$. No entanto, quando a concentração de flúor ultrapassa os níveis recomendados, torna-se um fator de risco para fluorose dentária ${ }^{1}$. No Brasil, o valor máximo permitido para a concentração de flúor nas águas de abastecimento público é de 1,5 $\mathrm{mgF} / \mathrm{l}$ (miligrama de flúor por litro) ${ }^{3}$. O controle dos teores de flúor nessas águas faz-se necessário para a manutenção desse elemento em níveis desejados ${ }^{4}$.

A portaria n. 2.914/2011 ${ }^{3}$, do Ministério da Saúde, dispõe sobre os parâmetros de controle e de vigilância da qualidade da água para consumo humano; entretanto, suas disposições não se aplicam às águas minerais ou às adicionadas de sais, destinadas ao consumo humano após o envasamento. $\mathrm{O}$ decreto-lei n. 7.841/1945 ${ }^{5}$, conhecido como Código de Águas Minerais, e ainda hoje em vigor, estabelece o que são águas minerais. Por sua vez, a Resolução de Diretoria Colegiada n. 274/2005 (RDC 274/2005)6, emitida pela Agência Nacional de Vigilância Sanitária (Anvisa), e que aprova o regulamento técnico para águas envasadas, conceitua as águas adicionadas de sais.

A indústria de água mineral está presente em todas as grandes regiões geográficas do mundo ${ }^{7}$. No Brasil, ao final de 2012, existiam 1.042 Concessões de Lavra de água mineral ativas ${ }^{7}$. Segundo dados apurados dos Relatórios Anuais de Lavra (RAL), o crescimento na produção de água mineral envasada, em 2012, ficou em torno de $10,4 \%{ }^{7}$. A produção anual total declarada de 6,98 bilhões de litros corresponde a apenas $40 \%$ do consumo estimado do país ${ }^{7}$. Entre os estados que apresentaram maior incremento no volume de produção de água mineral envasada, de 2011 para 2012, está o Ceará, que alcançou $7 \%$ da produção brasileira ${ }^{7}$. Além disso, a partir de 2006, especialmente no Ceará, detectou-se um número crescente de empresas envasadoras de águas adicionadas de sais ${ }^{8}$.

É preciso verificar se a presença de flúor nas águas envasadas ocorre em quantidade suficiente para prevenir a cárie, ou ainda, se representa risco significativo de fluorose, pois, assim, a população poderá se beneficiar dessas informações antes de decidir qual água consumir. A literatura tem demonstrado a importância desse assunto, tendo em vista o número de trabalhos publicados ${ }^{9-15}$; entretanto, mesmo com a vigência do Código de Águas Minerais, algumas portarias e resoluções foram criadas e outras revogadas, desde a publicação de alguns artigos. Considerando a relevância desses dois aspectos (biológico e legal) e o aumento na produção de águas envasadas, este estudo teve como objetivos: comparar as concentrações de flúor presentes nas diferentes marcas de águas envasadas comercializadas no estado do Ceará com aquelas declaradas nos rótulos das embalagens, e fazer uma análise crítica das normas legais sobre o tema.

\section{Materiais e método}

Tratou-se de um estudo transversal. Foram analisadas, quanto à concentração de flúor, 22 amostras distintas de águas envasadas para consumo humano. As águas foram adquiridas em supermercados de várias regiões do estado do Ceará durante o mês de janeiro de 2014. Buscou-se incluir nesta pesquisa, todas as marcas de águas minerais ou adicionadas de sais disponíveis no momento da compra, nos supermercados visitados, com exceção daquelas que haviam sido gaseificadas artificialmente.

Inicialmente, as águas foram armazenadas em condições de temperatura e iluminação semelhantes às das prateleiras dos supermercados, em suas embalagens originais. Foram coletadas dos rótulos dessas embalagens as seguintes informações: tipo de água (mineral ou adicionada de sais); tipo e volume do recipiente; classificação quanto à presença de flúor (fluoretada ou não); local de origem; concentração de flúor (quando relatada). Posteriormente, uma amostra de cada recipiente foi transferida para frascos de polietileno de $10 \mathrm{ml}$, que foram acondicionados em uma caixa de isopor e transportados para análise. Todos os frascos foram numerados de forma a possibilitar posteriormente a identificação dos seus conteúdos.

As análises foram realizadas em duplicata, por meio do método eletrométrico, utilizando-se um potenciômetro Orion EA940 acoplado a um eletrodo Orion 9609 BN, sob agitação magnética, com $1 \mathrm{ml}$ da amostra adicionado a $1 \mathrm{ml}$ de Total Ionic Strength Adjustment Buffer-Orion (Tisab II). Antes da leitura das amostras, foi feita uma calibração em triplicata, com soluções de flúor cujas concentrações eram previamente conhecidas e variavam de 0,1 a 1,6 mgF/l. Essas soluções foram preparadas a partir da diluição de uma solução padrão de flúor a $100 \mathrm{mgF} / \mathrm{l}$ (Orion) em água deionizada. Todas as leituras (de calibração e das amostras) foram obtidas em milivolts $(\mathrm{mV})$, tiveram suas médias aritméticas calculadas e foram convertidas para $\mathrm{mgF} / \mathrm{l}$ com o auxílio de uma planilha de cálculos (Microsoft Excel). A concentração de flúor encontrada em cada amostra foi comparada à impressa no rótulo da embalagem original.

Adicionalmente, foram feitas buscas minuciosas por leis, resoluções, portarias, e outros documentos oficiais em vigor, relacionados ao tema em questão, com a finalidade de subsidiar e dar robustez ao trabalho. A partir dos resultados laboratoriais, e das normas legais encontradas, fez-se uma análise crítica do assunto. 


\section{Resulltados}

A Tabela 1 mostra as informações contidas nos rótulos das águas estudadas e os resultados encontrados durante as análises da concentração de flúor nessas águas. Dentre as amostras, 90,9\% eram águas minerais e $9,1 \%$ águas adicionadas de sais. A maioria era comercializada em garrafas de 500 $\mathrm{ml}(40,9 \%)$, classificada como fluoretada $(72,7 \%)$ e originária dos estados da região Nordeste do Brasil $(72,7 \%)$. As concentrações de flúor encontradas variaram de 0,01 a $0,36 \mathrm{mgF} / \mathrm{l}$.

Tabela 1 - Águas envasadas comercializadas no Ceará, segundo informações contidas nos rótulos e concentrações de flúor encontradas durante análises laboratoriais

\begin{tabular}{|c|c|c|c|c|c|c|}
\hline Amostra & Tipo & Recipiente & $\begin{array}{c}\text { Classificada } \\
\text { como } \\
\text { fluoretada }\end{array}$ & Local de origem & $\begin{array}{c}\text { Concentração } \\
\text { de flúor } \\
\text { informada }\end{array}$ & $\begin{array}{c}\text { Concentração } \\
\text { de flúor } \\
\text { encontrada }\end{array}$ \\
\hline 1 & Mineral & Garrafa $500 \mathrm{ml}$ & Não & Ceará & Não constava & 0,03 \\
\hline 2 & Mineral & Botija $5000 \mathrm{ml}$ & Sim & Ceará & 0,01 & 0,04 \\
\hline 3 & Mineral & Garrafa $1500 \mathrm{ml}$ & Sim & Bahia & 0,01 & 0,02 \\
\hline 4 & Mineral & Garrafa $500 \mathrm{ml}$ & Não & Paraíba & Não constava & 0,02 \\
\hline 5 & Mineral & Garrafa $300 \mathrm{ml}$ & Sim & São Paulo & 0,05 & 0,03 \\
\hline 6 & Mineral & Garrafa $510 \mathrm{ml}$ & Sim & São Paulo & 0,05 & 0,04 \\
\hline 7 & Mineral & Garrafa $500 \mathrm{ml}$ & Não & Piauí & Não constava & 0,02 \\
\hline 8 & Mineral & Garrafa $1500 \mathrm{ml}$ & Sim & Alagoas & 0,03 & 0,01 \\
\hline 9 & Mineral & Garrafa $1500 \mathrm{ml}$ & Sim & Bahia & 0,06 & 0,02 \\
\hline 10 & Mineral & Garrafa $500 \mathrm{ml}$ & Sim & Bahia & 0,23 & 0,13 \\
\hline 11 & Mineral & Garrafa $300 \mathrm{ml}$ & Sim & Minas Gerais & 0,11 & 0,09 \\
\hline 12 & Mineral & Garrafa $300 \mathrm{ml}$ & Sim & São Paulo & 0,04 & 0,06 \\
\hline 13 & Mineral & Garrafa $500 \mathrm{ml}$ & Não & França & 0,06 & 0,05 \\
\hline 14 & Mineral & Garrafa $500 \mathrm{ml}$ & Sim & Ceará & 0,01 & 0,04 \\
\hline 15 & Adicionada de sais & Garrafa $500 \mathrm{ml}$ & Não & Não constava & Não constava & 0,01 \\
\hline 16 & Mineral & Botijão 20000 ml & Sim & Rio Grande do Norte & 0,34 & 0,20 \\
\hline 17 & Adicionada de sais & Botijão 20000 ml & Não & Ceará & Não constava & 0,36 \\
\hline 18 & Mineral & Botijão 20000 ml & Sim & Ceará & 0,12 & 0,08 \\
\hline 19 & Mineral & Garrafa $500 \mathrm{ml}$ & Sim & Ceará & 0,08 & 0,05 \\
\hline 20 & Mineral & Garrafa $500 \mathrm{ml}$ & Sim & Ceará & 0,03 & 0,04 \\
\hline 21 & Mineral & Copo $200 \mathrm{ml}$ & Sim & Ceará & 0,01 & 0,02 \\
\hline 22 & Mineral & Copo $200 \mathrm{ml}$ & Sim & Alagoas & 0,03 & 0,02 \\
\hline
\end{tabular}

\section{Discussão}

Neste estudo, 90,9\% das águas adquiridas eram classificadas como minerais. Parece simplório dizer que uma água é mineral, mas à luz da legislação, pode não ser tão óbvio. É salutar conduzir o estudo das concentrações de flúor em águas envasadas em paralelo com a observação da legislação relacionada ao tema, que é composta por regras que, por vezes, complementam-se, outras vezes, contradizem-se, e que em alguns momentos não trazem informações suficientes para se chegar a uma conclusão.
A própria classificação e as definições dessas águas são pontos que geram dúvidas. O Código de Águas Minerais ${ }^{5}$ traz os seguintes conceitos:

- Águas minerais são aquelas provenientes de fontes naturais ou de fontes artificialmente captadas, que apresentam composição química ou propriedades físicas ou físico-químicas distintas das águas comuns, com características que lhes confiram uma ação medicamentosa ${ }^{5}$. 
A atribuição de ação medicamentosa pode ser comprovada de forma imediata, por meio de características de composição e propriedades pré-estabelecidas; ou mediante observações repetidas, estatísticas completas, documentos de ordem clínica e de laboratório ${ }^{5}$.

- Águas potáveis de mesa são as águas de composição normal, provenientes de fontes naturais ou de fontes artificialmente captadas, que preencham tão somente as condições de potabilidade para a região $0^{5}$.

Já a RDC $274 / 2005^{6}$, que não pode se sobrepor ao Código de Águas Minerais, mas que deve estar em sintonia com esse, classifica e define as águas envasadas conforme segue.

- Água mineral natural é a aquela obtida diretamente de fontes naturais ou por extração de águas subterrâneas, caracterizada pelo conteúdo definido e constante de determinados sais minerais, oligoelementos e outros constituintes, considerando as flutuações naturais ${ }^{6}$.

Observa-se que não é citada a necessidade de comprovação de ação medicamentosa. Talvez essa definição seja mais atual e sensata, tendo em vista a dificuldade que pode existir para se aferir uma inconteste e comprovada ação medicamentosa, mas, dessa forma, o regulamento ignora uma exigência contida no Código de Águas Minerais.

- Água natural, que difere da água mineral natural pelo fato de seus sais minerais, oligoelementos e outros constituintes apresentarem-se em níveis inferiores aos mínimos estabelecidos para a mineral ${ }^{6}$.

Pode-se perceber que esse tipo de água equivale ao que no Código de Águas Minerais é chamado de “águas potáveis de mesa".

- Água adicionada de sais é a água para consumo humano, preparada e envasada com a adição obrigatória de um ou mais sais previstos em regulamento específico ${ }^{6}$.

Trata-se de uma modalidade de água envasada não prevista no Código de Águas Minerais, mesmo porque não se trata de água mineral, e sim de um alimento industrializado, para o qual os requisitos exigidos são outros. Deve ser ressaltado, o fato de que nenhum dos sais de adição obrigatória nessas águas contém flúor em sua formulação ${ }^{6}$.

Outro aspecto de enorme relevância é a classificação de uma água mineral como fluoretada. Nem o Código de Águas Minerais, nem a RDC 274/2005 estabelecem parâmetros mínimos para isso ${ }^{5,6}$. O Código de Águas Minerais ${ }^{5}$ estabelece que as águas minerais serão classificadas de acordo com o elemento predominante, podendo ser mistas as que contiverem substâncias raras dignas de nota. O conceito de substâncias raras dignas de nota, entre as quais está o flúor, e, principalmente, a concentração mínima dessas substâncias na água mineral para fins de classificação, já foram discutidos na Comissão Permanente de Crenologia (CPC) do Departamento Nacional de Produção Mineral (DNPM), órgão vinculado ao Ministério de Minas e Energia (MME), conforme pode ser visto nas atas da $9^{\mathrm{a}}, 10^{\mathrm{a}}, 11^{\mathrm{a}}, 14^{\mathrm{a}}$ e $24^{\mathrm{a}}$ reuniões da $\mathrm{CPC}^{16-20}$. Apesar disso, não foi possível localizar nenhuma portaria ou outro documento legal que estabeleça a concentração mínima necessária para que uma água mineral possa ser classificada como fluoretada. No entanto, neste estudo, $72,7 \%$ das águas traziam em seus rótulos a classificação "fluoretada". Como essa classificação é feita? Quais os critérios adotados?

As águas minerais envasadas na Comunidade Europeia são classificadas como fluoretadas somente quando a concentração é maior que $1 \mathrm{mgF} /$ $L^{8}$. No Brasil, embora não tenha sido encontrada norma publicada sobre isso, uma concentração igual ou superior a $0,01 \mathrm{mgF} / \mathrm{l}$ já permite a classificação da água mineral como fluoretada ${ }^{8}$. Claro que há uma grande diferença entre as médias das temperaturas máximas europeias e brasileiras, e que o Brasil não deve simplesmente adotar, de forma equivocada, o padrão europeu para essa classificação. No entanto, classificar como fluoretadas, águas com concentrações a partir de $0,01 \mathrm{mgF} /$, pode induzir a população a acreditar que está consumindo um produto capaz de prevenir a cárie. Isso não ocorre em concentrações tão baixas ${ }^{21}$. A portaria ministerial $470 / 1999^{22}$ diz que não poderão constar no rótulo das embalagens, informações relativas a eventuais características, propriedades terapêuticas, expressões que supervalorizem a água, ou ainda qualquer designação suscetível de causar confusão ao consumidor. Para que se obtenha o máximo benefício do flúor na prevenção da cárie, aliado a um baixo risco de fluorose dentária, são necessárias concentrações de 45 a 94 vezes mais altas que $0,01 \mathrm{mgF} / \mathrm{l}$, a depender da média das temperaturas máximas anuais do local ${ }^{21}$.

O Código de Águas Minerais também não faz referência ao limite máximo de flúor permitido nas águas envasadas ${ }^{5}$. A RDC $274 / 2005^{6}$ diz apenas que devem constar as seguintes advertências nos rótulos:

- "contém fluoreto" quando o produto contiver mais que $1 \mathrm{mgF} / \mathrm{l}^{6}$;

- "o produto não é adequado para lactentes e crianças com até 7 anos de idade", quando contiver mais que $2 \mathrm{mgF} / \mathrm{l}^{6}$;

- "o consumo diário do produto não é recomendável, pois contém fluoreto acima de $2 \mathrm{mg} / \mathrm{l}$ ", quando contiver mais que $2 \mathrm{mgF} / \mathrm{l}^{6}$. 
Para as águas de abastecimento público, a portaria $2.914 / 2011^{3}$ estipula em $1,5 \mathrm{mgF} / \mathrm{l}$ o valor máximo de flúor permitido para que uma água seja considerada potável. Já a portaria $635 / 75^{23}$ estipula $1,7 \mathrm{mgF} / 1$ como o máximo recomendável, sempre considerando a temperatura local.

Neste estudo, todas as águas classificadas como fluoretadas traziam em seus rótulos o teor de flúor presente. Uma amostra, de origem francesa, também trazia no rótulo o teor de flúor que continha, mesmo sem estar classificada como fluoretada. Tomando o valor mínimo de $0,01 \mathrm{mgF} / \mathrm{l}$ como critério para classificação de águas fluoretadas, as quatro amostras de água mineral que não haviam sido assim classificadas apresentaram concentrações suficientes para que isso fosse feito. A maior concentração encontrada $(0,36 \mathrm{mgF} / \mathrm{l})$ foi em uma água adicionada de sais, que não trazia essa informação no rótulo. Foram observadas variações percentuais, para mais e para menos, entre os teores informados nos rótulos e aqueles obtidos durante as análises, assim como encontrado em outros trabalhos ${ }^{11-13,24,25}$. Algumas dessas diferenças podem ser atribuídas a flutuações naturais do teor de flúor na fonte de captação principalmente se for levado em consideração o caráter transversal do estudo. Deve-se considerar ainda uma limitação quanto à precisão do método, quando da análise de amostras com concentrações ínfimas. Algumas variações foram percentualmente grandes, sugerindo imprecisão nas informações dos rótulos.

Todas as amostras mostraram-se seguras quanto ao risco de fluorose dentária, corroborando os resultados de Souza et al. ${ }^{10}$ (2009); Sayed et al. ${ }^{14}$ (2011); Terreri et al. ${ }^{26}$ (2009); e Bastos et al. ${ }^{27}$ (2001), e divergindo daqueles obtidos por Villena et al. ${ }^{28}$ (1996), nos quais algumas amostras evidenciaram-se capazes de causar fluorose dentária severa.

Apesar das variações encontradas, o que mais chamou a atenção foi a baixa concentração de flúor observada em todas as amostras, evidenciando a inexistência de ação preventiva anticárie, inclusive naquelas classificadas como fluoretadas. Concentrações baixas de flúor em águas minerais também foram identificadas em outros estudos nacionais e internacionais ${ }^{10-12,14,15,26,27,29}$. O estado do Ceará tem regiões com condições climáticas diferentes (sertão, serras e praias), mas mesmo naquelas em que a média das temperaturas máximas anuais situa-se acima de $32,5^{\circ} \mathrm{C}$, a concentração mínima de flúor na água ingerida deve se manter pelo menos em 0,45 $\mathrm{mgF} / \mathrm{h}^{21}$. Isso mostra a importância da mensuração e do monitoramento da presença de flúor nas águas envasadas, e, também que o uso do termo "fluoretada”, em rótulos de águas com concentração de flúor insignificante para a prevenção da cárie, pode ser inapropriado.

\section{Conclusão}

As concentrações de flúor encontradas nas águas analisadas não oferecem risco de fluorose à população, todavia são insuficientes para causar o efeito anticárie que se espera desse elemento, quando utilizado em teores ideais.

A legislação vigente sobre fluoretação de águas envasadas necessita de atualizações, a fim de se tornar mais objetiva e de criar novos critérios para o uso da expressão "água fluoretada" nos rótulos.

\section{Abstract}

Fluoridation of water for human consumption is a method of caries prevention that brings great social benefit, if kept at optimal levels. The increase in the production of bottled water emphasizes the need to verify whether fluoride presence in these waters occurs in sufficient quantity to prevent decay, or if it represents a significant risk of fluorosis. Objective: to compare the concentrations of fluoride present in bottled water to those declared on the labels, and to make a critical analysis of legal norms on the subject. Materials and method: this was a cross-sectional study, through which $22 \mathrm{sam}$ ples of bottled water sold in state of Ceará, Brazil, were analyzed. Analyses were performed in duplicate by the electrometric method, and results were compared to those printed on the labels. Detailed searches by laws, resolutions, ordinances, and other official documents in force, related to the topic were performed. Results: the fluoride concentrations found ranged from 0.01 to 0.36 $\mathrm{mgF} / \mathrm{l}$. Although $72.7 \%$ of the samples were classified as fluoridated, the fluoride concentrations observed were shown to be insufficient for caries prevention. As for the rules, situations where they are not clear or even divergent were found. Conclusion: the current legislation on the subject requires updates to become more objective and to create new criteria on the use of the term "fluoridated water".

Keywords: Bottled water. Fluorides. Health legislation. Product labeling.

\section{Referências}

1. Ramires I, Grec RHC, Cattan L, Moura PG, Lauris JRP, Buzalaf MAR. Avaliação da concentração de flúor e do consumo de água mineral. Rev Saúde Pública 2004; 38(3):459-65.

2. Frias AC, Narvai PC, Araújo ME, Zilbovicius C, Antunes JLF. Custo da fluoretação das águas de abastecimento público, estudo de caso: município de São Paulo, Brasil, período de 1985-2003. Cad. Saúde Pública 2006; 22(6):1237-46.

3. Brasil. Ministério da Saúde. Portaria n. 2.914, de 12 de dezembro de 2011. Diário Oficial da República Federativa do Brasil, Brasília, 14 dez 2011, seção 1, p. 39.

4. Moimaz SAS, Saliba O, Chiba, FY, Saliba NA. External control of the public water supply in 29 Brazilian cities. Braz Oral Res 2012; 26(1):12-28.

5. Brasil. Decreto-lei n. 7.841, de 8 de agosto de 1945. Código de Águas Minerais. Diário Oficial da República Federativa 
do Brasil, Brasília, 20 ago 1945 [citado 2014 jun. 15]. Disponível em URL: http://www.planalto.gov.br/ccivil_03/decreto-lei/1937-1946/Del7841.htm.

6. Brasil. Ministério da Saúde. Agência Nacional de Vigilância Sanitária. Resolução de Diretoria Colegiada - RDC n. 274, de 22 de setembro de 2005. Diário Oficial da República Federativa do Brasil, Brasília, 23 set 2005, seção 1, p. 376.

7. Brasil. Ministério de Minas e Energia. Departamento Nacional de Produção Mineral. Sumário mineral 2013 - água mineral. Brasília: Ministério de Minas e Energia; 2013 [citado 2014 Jun 11]. Disponível em URL: https://sistemas.dnpm.gov.br/publicacao/mostra_imagem. asp?IDBancoArquivoArquivo=8963.

8. Brasil. Ministério de Minas e Energia. Perfil da água mineral. Brasília: Ministério de Minas e Energia; 2009 [citado 2014 Jun 11]. Disponível em URL: http://www.mme.gov.br/ sgm/galerias/arquivos/plano_duo_decenal/a_mineracao_brasileira/P31_RT57_Perfil_da_xgua_Mineral.pdf.

9. Garbin CAS, Martins RJ, Garbin AJI, Moimaz SAS. Necessidade de regulamentação das propagandas e readequação dos rótulos das embalagens de águas minerais. Rev Inst Cienc Saúde 2003; 21(4):387-9.

10. Souza CFM, Paredes SO, Forte FDS, Sampaio FC. Fluoride content of bottled water commercialized in two cities of northeastern Brazil. Braz J Oral Sci 2009; 8(4):206-9.

11. Bulcão LN, Rebelo MAB. Avaliação da concentração de flúor em águas minerais e refrigerantes à base de guaraná comercializados em Manaus-AM. Rev Odonto Cienc 2009; 24(3):240-3.

12. Mills K, Falconer S, Cook C. Fluoride in still bottled water in Australia. Aust Dent J 2010; 55:411-6.

13. Mythri H, Chandu GN, Prashant GM, Reddy VVS. Fluoride and bacterial content of bottled drinking water versus municipal tap water. Indian J Dent Res 2010; 21(4):515-7.

14. Sayed N, Ditterich RG, Pinto MHB, Wambier DS. Concentração de flúor em águas minerais engarrafadas comercializadas no município de Ponta Grossa-PR. Rev Odontol Unesp 2011; 40(4):182-6.

15. Muzinic D, Vrcek D, Malcic AI, Matijevic J, Grget KR, Krmek SJ. The concentration of fluorides in tap water and commercial bottled beverages. Acta Stomatol Croac 2012; 46(1):23-30.

16. Brasil. Ministério de Minas e Energia. Departamento Nacional de Produção Mineral. Ata da $9^{a}$ reunião da Comissão Permanente de Crenologia. Brasília: Ministério de Minas e Energia; 2007 [citado 2014 Jun 11]. Disponível em URL: http://www.dnpm.gov.br/mostra_arquivo. asp?IDBancoArquivoArquivo=3308.

17. Brasil. Ministério de Minas e Energia. Departamento Nacional de Produção Mineral. Ata da $10^{\mathrm{a}}$ reunião da Comissão Permanente de Crenologia. Brasília: Ministério de Minas e Energia; 2007 [citado 2014 Jun 11]. Disponível em URL: http://www.dnpm.gov.br/mostra_arquivo. asp?IDBancoArquivoArquivo=3139.

18. Brasil. Ministério de Minas e Energia. Departamento Nacional de Produção Mineral. Ata da $11^{\mathrm{a}}$ reunião da Comissão Permanente de Crenologia. Brasília: Ministério de Minas e Energia; 2007 [citado 2014 Jun 11]. Disponível em URL: http://www.dnpm.gov.br/mostra_arquivo. asp?IDBancoArquivoArquivo=3138.

19. Brasil. Ministério de Minas e Energia. Departamento Nacional de Produção Mineral. Ata da $14^{\mathrm{a}}$ reunião da Comissão Permanente de Crenologia. Brasília: Ministério de Minas e Energia; 2008 [citado 2014 Jun 11]. Dispo- nível em URL: http://www.dnpm.gov.br/mostra_arquivo. asp?IDBancoArquivoArquivo=3137.

20. Brasil. Ministério de Minas e Energia. Departamento Nacional de Produção Mineral. Ata da $24^{\mathrm{a}}$ reunião da Comissão Permanente de Crenologia. Brasília: Ministério de Minas e Energia; 2010 [citado 2014 Jun 11]. Disponível em URL: http://www.dnpm.gov.br/mostra_arquivo. asp?IDBancoArquivoArquivo=5033.

21. CECOL/USP - Centro Colaborador do Ministério da Saúde em Vigilância da Saúde Bucal. Consenso técnico sobre classificação de águas de abastecimento público segundo o teor de flúor. São Paulo: Faculdade de Saúde Pública da Universidade de São Paulo; 2011.

22. Brasil. Ministério de Minas e Energia. Portaria n. 470, de 24 de novembro de 1999. Diário Oficial da República Federativa do Brasil, Brasília, 25 nov 1999, seção 1, p. 29.

23. Brasil. Ministério da Saúde. Portaria n. 635, de 26 de dezembro de 1975. Diário Oficial da República Federativa do Brasil, Brasília, 30 Jan 1976 [citado 2014 Jun 15]. Disponível em URL: http://proweb.procempa.com.br/pmpa/prefpoa/ sms/usu_doc/portaria635.pdf.

24. Valsecki Jr. A, Brandão IMG. Análise da concentração de flúor em águas minerais na região de Araraquara, Brasil. Rev Panam Salud Publica 1998; 4(4):238-42.

25. Grec RHC, Moura PG, Pessan JP, Ramires I, Costa B, Buzalaf MAR. Concentração de flúor em águas engarrafadas comercializadas no município de São Paulo. Rev. Saúde Pública 2008; 42(1):154-7.

26. Terreri ALM, Santos CCM, Lopes MRV, Silva RFM, Rodrigues JCS. Avaliação da concentração de flúor em águas minerais engarrafadas disponíveis no comércio. Rev. Inst Adolfo Lutz 2009; 68(3):354-8.

27. Bastos JRM, Buzalaf MR, Levy FM, Ribeiro TT, Mazzone, FHR. Concentração de flúor em água mineral engarrafada e de fontes naturais das cidades de Lindóia, Águas de Lindóia e Serra Negra, Brasil. Rev. Fac. Odontol. Univ. Passo Fundo 2001; 6(1):15-9.

28. Villena RS, Borges DG, Cury JA. Avaliação da concentração de flúor em águas minerais comercializadas no Brasil. Rev. Saúde Pública 1996; 30(6):512-8.

29. Martins RJ, Garbin CAS, Garbin AJI, Moimaz SAS. Alerta aos consumidores! A concentração de flúor descrita no rótulo das águas minerais protege contra as cáries? Rev Paul Odontol 2006; 28(2):20-2.

\section{Endereço para correspondência:}

Arinilson Moreira Chaves Lima

Universidade Estadual Paulista Júlio de Mesquita Filho

José Bonifácio, no1193 - Vila Mendonça

16015-050 Araçatuba-SP

E-mail: arinilsonchaves@hotmail.com

Recebido: 05/08/2014. Aceito: 14/11/2014. 